\title{
Social Informatics Experience: A Case Study on Learning and Teaching Sociological Basics in a Technical Context
}

\author{
Christa Weßel \\ Königstr. 43, 26180 Rastede, Germany \\ Corresponding author: Christa Weßel (mail@christa-wessel.de)
}

Independent Expert - freelance scientist, adviser, lecturer and author in organizational development, social informatics and higher education,

\begin{abstract}
To be able to play an active role in the design, creation and development of a networked society, students, scholars and practitioners need basic knowledge in social informatics. Students at a university of applied sciences attended a one-term seminar that consisted of eight two-day workshops. The students learned and used theories, concepts and methods of social informatics (SI), focusing on the sociological part of SI. The learning and teaching approach is grounded in competency-based learning. It enables students to explore a certain field. This is implemented by means of organization development, project-based learning, agile learning and teaching plus blended learning. It empowers teachers and students to work together efficiently, effectively and with joy. To learn how and why this approach worked, an embedded case study investigated the design, implementation and evaluation of the workshop series. Finally, the paper describes impediments to the communication and understanding of the term and the field of social informatics and sketches ideas how to deal with it concerning study programmes and the value social informatics can contribute to challenges like a pandemic.
\end{abstract}

\section{Keywords}

Social informatics; Socioinformatics; Project-based learning; Continued multidisciplinary projectbased learning; CM-PBL; Competency-based learning; CBL; Agile learning; Blended learning; Organization development.

\footnotetext{
Citation: Weßel, C. (2021). Social Informatics Experience: A Case Study on Learning and Teaching Sociological Basics in a Technical Context. Acta Informatica Pragensia, 10(3), 211-235. https://doi.org/10.18267/j.aip.170 


\section{Education in Social Informatics}

When did the digital era start? Was it with the World Wide Web and the Internet during the 1980s and 1990s? Or earlier, with the astronauts and the men on the moon? Whenever it started, the COVID-19 pandemic showed from its beginning in 2020 how useful and sometimes harmful information and communication technologies can be in the mastering of such a worldwide challenge. This relates to nearly all aspects: health care systems, government, education, public services, economics and of course the private life and physical and socio-psychological well-being of people. Communication in social media is of special relevance (Darius and Stephany, 2020).

Both are important: technology and social aspects. Social informatics (SI) strives to cover both.

SI can be broadly defined as a research field that focuses on the research of sociotechnical interactions at different levels in connection with the development of the information society, including the social aspects of computerization and informatization, which can be structured into three main areas: interactions between ICT and humans, ICT applications in the social sciences, and ICT applications as a social sciences research tool. (Smutny and Vehovar, 2020, p. 537)

In a broader context for the daily life of social informatics, I propose the following definition of SI, translated from Weßel (2021a, pp. 20-21):

Social informatics deals with the interrelationship of information and communication technology and social change. This affects individuals, groups, (international) organizations (companies, public authorities, associations, etc.) plus local communities, states and international communities of states.

The task of social informatics is to support by research and development the design, implementation and maintenance of information systems for the benefit of individuals, groups and society, so that those who develop, build, sell and maintain these systems tailor technology to people and not conversely. To afford this, social informatics builds upon disciplines such as sociology, psychology, philosophy, anthropology, historical sciences, economics, law and - of course - computer sciences.

Especially the World Wide Web and the Internet have a lasting effect on our daily life: Web 1.0 (static data presentation), Web 2.0 (the reader turns into a player, for instance in social media), Web 3.0 (semantic) and the Internet of Things, Internet 4.0.

To be able to play an active role in the design, creation and development of a networked society, students, scholars and practitioners need basic knowledge in social informatics.

Interesting education programmes and materials stem from the United Kingdom, Russia, South Africa, Slovenia, the United States and Germany. Research institutes in Scotland, Germany, Russia, Italy and the Middle East focus on social informatics. Smutny and Vehovar (2020) identify five to seven schools of social informatics distributed worldwide. The particular scientific scope affects the design of study programmes and the diversity of contents. One of the early study programmes in social informatics was implemented in Slovenia. The Faculty of Social Sciences at the University of Ljubljana (2021) has offered a study programme in social informatics since 1984 (Smutny, 2016).

In Germany, the term social informatics is not widely known. Computer scientists speak about "Informatik und Gesellschaft", information technology and society. This topic has been part of curricula in computer sciences for decades. The 2000 and 2001 lecture topics of Professor Wolfgang Coy at the Humboldt University Berlin are a fine example (Coy, 2000). In my view, the headlines are still applicable with minor adaptations in today's seminar on social informatics. Only a few universities in Germany offer a particular degree programme in social informatics, for instance the University of Kaiserslautern. The university calls the bachelor and master programmes "Socioinformatics" (TU Kaiserslautern, 2021). 
Another approach is to focus in a study path on social informatics (HFU, 2021). From 2015 at the Hochschule Furtwangen (HFU), a university of applied sciences, offered a SI branch of study in the bachelor programme "IT Product Management". The study programme included two modules on social informatics during the fourth term, "Information Technology and Its Social Context" and "Social Nets". The modules combined lectures and seminars. During the summer term 2017 and the winter term 2017/2018, a visiting lecturer was hired to perform these modules. With the consent of the university, she merged them in the workshop series "Social Informatics". This was her answer to the question, "How can students learn about SI?" To provide high quality, she performed an attending study as a participating observer: as a teacher and a researcher, performing the study "Social Informatics Experience: Learning and Teaching Sociological Basics in a Technical Context" (short: Social Informatics Experience). From here on, I report and reflect in the first person. The paper is written in a personal style as Stake advocates it (Stake, 1995, p. 135).

Based on the finding that competency-based learning enriches students' learning success and satisfaction (Jones et al., 2002) and on the development of continued multidisciplinary project-based learning (Weßel and Spreckelsen, 2009) plus former experience with the transfer of CM-PBL to seminar settings (Weßel, 2010 and 2015), I assumed that the CM-PBL approach can be transferred to a workshop series setting, that agile learning and teaching support this, and that students' commitment, success and satisfaction is high in this setting.

The aim of this paper is to answer the research questions, "How can the concepts of continued multidisciplinary project-based learning (CM-PBL) and agile learning and teaching (ALT) be transferred to a one-term seminar setting in social informatics?" - "Does it work?" - "How does it work?" - "Why does it work?" - "What is necessary to make it happen?" The study should answer especially the "how" questions to offer interested colleagues, students and other stakeholders in learning and teaching, such as university managers, an example and perhaps inspiration for their own work. The learning and teaching approach described here is not restricted to SI. It can be used for other topics and fields. The design of the seminar as a workshop series, the data and the conclusion are intended to be used and perhaps useful in further research, decision making and application especially in the multi- and trans-disciplinary field of social informatics.

The paper is organized as follows. After a short description of some didactic basics in "Learning and Teaching", which are elaborated in Appendix A, the method of case study considering action research and triangulation is outlined with immediate references to the application in the study "Social Informatics Experience". The section "SI Workshop Series" presents the results of the study. The final subsection of the results contains a students' design for a study programme for social informatics. This builds the transition to the discussion and the conclusion.

\section{Learning and Teaching}

Students need a comprehensive education in subject-specific, methodological and social competencies and skills. Learning in realistic scenarios is based on the theory of cognitive learning: learning by insights and on a model empowers the learner to explore a topic autonomously, to use scientific methods and to develop solutions. This enhances the learner's motivation and improves the learning outcome in the short, medium and long term (Felder et al., 2000; Slavin, 1996). Teachers envision themselves as facilitators, mentors and guides (Weßel and Spreckelsen, 2009). The purpose of competency-based learning (CBL) is to empower students to develop these skills (Jones et al., 2002). Several studies and experience during the last decades show that CBL and its realization via approaches such as project-based learning (PBL) and continued multidisciplinary project-based learning (CM-PBL) empower students to learn efficiently, effectively, with joy and holistically (e.g., Felder et al., 2000; Weßel and Spreckelsen, 2009). This is enriched 
by the application of agile learning and teaching (ALT) and blended learning (BL). Appendix A describes these theories, concepts and approaches in some detail.

As I am an organization developer, I use theories, concepts and methods of organization development (OD). The goal and purpose of OD is to pilot change for the well-being of both the organization and the people inside and beyond (Argyris and Schön, 1978; Cooperrider et al., 2008; Cummings, 2008; DeMarco and Lister, 1999; Laloux, 2014; Senge, 2006; Sennett, 2012; Wiegers, 1996). OD can be applied transorganizationally, organizationally, in a department, in projects and other settings, wherever people interact. Transferred to the implementation of a seminar, this means that a teacher as the OD manager in charge adopts this attitude and integrates students - the OD staff - and the university administration and colleagues - OD staff and management - into the design, planning, management and implementation process of a particular seminar. The students' salary is their learning, success and certificate. Appendix B describes some basics of OD.

\section{Case Study Considering Action Research and Triangulation}

The study "Social Informatics Experience" was performed as a case study because there were two workshop series and, most importantly, because case studies strive to understand, to get new insights. and to answer how and why something happens as it happens and how and why something works (Stake, 1995, p. 1; Yin, 2018, p. 2). The case study approach uses especially qualitative research methods and, in certain designs, also quantitative methods (Scholz and Tietje, 2002, p. 14). It strives to take into account triangulation. The researcher can either be only an observer or both a researcher and a participant. In the study, I acted as a researcher and a participant, the teacher. The students are also researchers in so far as this study follows Lewin's action research (Lewin, 1946). The following sub-sections describe the methods and their application in the study.

\subsection{Case study}

A case study takes place in the field. "In the field" means to perform a study not in a laboratory but in the "real" world. A case is a defined unit that can be explored and analysed. Case studies are used in education and research. In research, the purpose of case studies is to gain insights, to understand, to develop theories, models, concepts and hypotheses and - depending on the design - to test a hypothesis. The dimension and classification of case studies can be described by the aspects of design, motivation, epistemological status, purpose, data, format and synthesis (Scholz and Tietje, 2002, p. 10). There are four basic case study designs, which can be sketched in a 2x2 table (Yin, 2018, p. 48). One dimension is the number of cases: single or multiple. The other dimension is the number of analysed units. A holistic case study has one unit. If more than one unit is analysed in a case, it is an embedded case study. The steps of a case study are: definition of research questions and case(s), sketching of the research process, performance of data collection, analysis and conclusion.

The study "Social Informatics Experience" is designed as an embedded two-case study. The units of the cases are "students (socio-demographic attributes)", "commitment", "success" and "satisfaction". The two editions of the workshop series build the two cases: case 1 in the summer term 2017; case 2 in the winter term 2017/2018. The motivation is both intrinsic and extrinsic. It is intrinsic in that the researcher is simultaneously the teacher and is interested in the well-being of the students and success of their learning. It is extrinsic in that the design of the seminar as a workshop series, the data and the conclusion can be used and perhaps useful in further research, decision making and application. The epistemological status is explorative, descriptive and explanatory. Explorative means learning whether such an approach is possible in such a setting. It is descriptive by the use of the concepts of PBL and agile learning and teaching. Explanatory means formulating the hypothesis that students will learn more efficiently, effectively and with more joy than in other, conventional settings. The purpose of this study was 
action/application. The data were both qualitative and quantitative. It should be noted here that the quantitative data are to be seen as part of the description without any statistical tests. The study's format is structured with three phases of data collection and by the design of the seminar as a workshop series. The synthesis, that is the knowledge integration, is based on the analysis and the interpretation of the collected data with awareness of conventional learning settings. The synthesis is elaborated in the discussion and in the conclusion and outlook sections.

\subsection{Action research}

The student knows the answer. The preceding sentence is inspired by the approach "the client knows the answer", attributed to organization developers such as Kurt Lewin, Chris Argyris and Donald Schön. Kurt Lewin (1890-1947) coined the term "action research" in the 1940s. His research and work as a consultant for companies and the government and work with the people in these organizations focused on group dynamics and change. Lewin became aware that only cooperation of scientists and practitioners offers relevant progress and new insights: "Socially, it does not suffice that university organizations produce new scientific insights. It will be necessary to install fact-finding procedures, social eyes and ears, right into social action bodies." (Lewin, 1946, p. 38)

He defined three steps: "planning, executing, and reconnaissance or fact-finding" (ibidem, p. 38). Scientists and practitioners perform these steps together. This approach answers four purposes: evaluation, to check whether the intended goals are achieved; learning, to gain insights on the strengths and weaknesses of an action or method; gaining material for both the planning of next steps and for revision or redesign. In the study "Social Informatics Experience" the practitioners were the teacher, the university administration and the students. The teacher designed the workshop series, all the practitioners were involved in the planning and the evaluation, the students and the teacher performed ("executed") the workshop series. The approach was formative. During the preparation and execution of the workshop series, the teacher and the students evaluated and adapted the workshop sub-topics to the needs, questions and suggestions of both the students and the teacher.

\subsection{Triangulation}

Qualitative research is characterised by openness, explication, subjectivity, reflection and interpretation (Strauss and Corbin, 1998, p. 7). It is an iterative process, maintained until saturation is reached. Qualitative studies are performed incrementally. The researcher goes into the field to learn about people, their life, their work, their needs and their ideas. The data collection is performed, for example, as observation or interviews and relies on textual formats. The high quality of the research is assured by triangulation (Ammenwerth et al., 2003; Stake, 1995, pp. 107-120; Yin, 2018, pp. 127-129). This means working with different sources of data, methods, observers and/or theories. The study "Social Informatics Experience" meets three of these.

The methods are both qualitative and quantitative. The qualitative research methods used here include observation, interviews and analysis of text documents (students' portfolios, teacher's blog, university website). Descriptive quantitative data and figures stem from the university website, the cases and the evaluation questionnaire in case 2. There are several data sources gained by the exploration of different units in the university context and the two cases. There was only one observer (researcher); thus, this triangulation criterion is not fulfilled. The study uses several theories and suppositions. These are competency-based learning, action research and organization development. Competency-based learning fosters students' short-term, medium-term and long-term learning success in professional and social skills. Action research is characterized by close cooperation between the researcher and the actors in the research object. Organization development is in turn based on theories, insights and methods from sociology, psychology, economics and didactics. 


\section{SI Workshop Series}

This section reports on the results. It starts with the research questions, the data and the setting. The workshop series follows with "Topics and contents" and cases 1 and 2. The workload is described for both cases together, as there are strong similarities. A students' design of a study programme for social informatics builds the transition to the following Discussion section.

\subsection{Research questions}

The study spans two workshop series. This should afford to reach a high quality in the development, performing and evaluation processes. Based on the finding that competency-based learning enriches students' learning success and satisfaction (Jones et al., 2002) and on the development of continued multidisciplinary project-based learning (Weßel and Spreckelsen, 2009) plus former experience with the transfer of CM-PBL to seminar settings (Weßel, 2010 and 2015), I assumed that the CM-PBL approach can be transferred to a workshop series setting, that agile learning and teaching supports this, and that students' commitment, success and satisfaction is high in this setting. This led to the following research questions:

"How can the concepts of continued multidisciplinary project-based learning (CM-PBL) and agile learning and teaching (ALT) be transferred to a one-term seminar setting in social informatics?" - "Does it work?" - "How does it work?" - "Why does it work?" - "What is necessary to make it happen?"

\subsection{Data}

Data were collected from November 2016 to January 2018 in three phases: context (the university), workshop series/cases 1 and 2. Qualitative data stem from observation, short group interviews (checkin/check-out on every workshop day), focus group interviews (workshops 5 and 8 in case 1) and texts (students' portfolios and own blog entries). Quantitative data include the description of the university on its website, the number of workshops and teaching units, numbers of students, participation and success rates in the proofs of performance and also the workload for both students and the teacher. The quantitative data are descriptive without further statistical testing.

\subsection{Setting}

The Hochschule Furtwangen University (HFU) is located in the southwest of Germany (HFU, 2021a). About five thousand students are enrolled in bachelor and master programmes. One of the bachelor programmes is "IT Product Management" with the major fields in either software processes or social informatics (HFU, 2021b). It started in the winter term 2015/2016 and, during the fourth term in 2017 and 2017/2018, it included two modules on social informatics, "Information Technology and Its Social Context" and "Social Nets". It should be noted that the contents of the study programme has changed in the meantime. Thus, the reader will not find the description of the 2017 modules on the current HFU website, but they are online available via Weßel (2018). The first run had to take place during the summer term 2017. At that time, 121 students were enrolled in the study programme "IT Product Management". Twelve of them, four women and eight men, completed the fourth term. They were the first students enrolled in 2015.

On 29 November 2016, I got an e-mail from a professor at the HFU. They were looking for a visiting lecturer in social informatics. He found my blog section on social informatics and decided to ask me whether I was interested in teaching the SI modules during the summer term 2017. During our phone conversation one day later, he also asked me to take part in the staffing procedure of a professorship in social informatics in January 2017. I accepted both. Although I wanted to stay a freelance lecturer, I knew that this procedure would be a good opportunity to become acquainted with the university and some 
colleagues, students and members of the administration, especially the office assistants at the Department of Computer Science, two month ahead of the semester.

The two modules covered overall 120 teaching units (each 45 minutes). The university accepted my proposal to merge them and to design and implement a setting with eight workshops (two days each) and two proofs of performance. The design started with questions on "What is social informatics?" I published the questions and a sketch of the proofs of performance in my blog on 24 February 2017 and discussed them with colleagues and former students (Appendix C). This led to the identification of the workshop topics, considering and integrating the requirements and contents that the university had included in the description of the modules.

The continued support of the two office assistants at the Department of Computer Science from the beginning in January 2017 until the end in January 2018 was crucial for the success. Furthermore, the students were involved. I sketched the structure and together we decided during the first workshop on aspects such as timetables for the proofs of performance plus the organization of the e-learning part of our work, using platforms for documentation and files and e-mail communication. During the terms, we adapted the topics and the timetable if the students or I asked for changes.

The workshops took place on Thursdays and Fridays every two or three weeks, starting at noon on Thursday and finishing on Friday afternoon. The breaks during the workshop days did not follow a strict timetable, only lunch was fixed: one hour, starting mostly at 12:30. For the shorter breaks everyone was in charge. I had to keep in mind the need for breaks. The students were required to announce the need for a break if I forgot it. The seminar room of the Department of Computer Science was large, about $15 \mathrm{~m}$ long by $12 \mathrm{~m}$ wide, overall about 180 square meters. Thus, we could put some tables aside to gain space for work in the room, for instance for the check-in/check-out.

We evaluated the satisfaction of both students and the teacher, formatively during the workshops in the check-in/check-out and in dialogues. This afforded to adapt the learning and teaching process and procedures in the course of the workshop series. On the whole, the students described their experience with the workshops, new insights and degree of satisfaction in their portfolios. I reported about my reflections and degree of satisfaction as the teacher in my blog on social informatics (Weßel, 2021b) and in a book on learning and teaching (Weßel, 2019, pp. 261-264).

\subsection{Workshop topics and contents}

The objective was to empower students to use theories, concepts and methods from social informatics for their work as IT product managers. They shall be able to take social, political and technical preconditions into account and to be aware of the social and ecological responsibility of IT product managers. As the technical aspects were objects of other modules, the workshops focused on the following topics:

1. Getting started: Social networks and electronic media.

2. Exploration and evaluation: What do the users need?

3. Internationalization and globalization: Life is a net.

4. Product management and ethics: The art of balance between the technically feasible and social consequences.

5. Life world and work world: In fact I live while I work.

6. Hackathon: Let's work ... and have fun.

7. Digital dexterity and Internet of Things: About handling the new.

8. Synopsis: It's all about communication. 
Further topics were definitions in informatics, sociology, economics plus group dynamics and team work, network, organization and stakeholder analysis, innovation, digital dexterity, agile management and appreciative inquiry.

The complete curriculum has been available for students and the public in German since 2017 and also in English since December 2021 (Weßel, 2018). Appendix C gives an overview on the online curriculum with its topics such as introduction, contents and learning objectives, workshop series, proofs of performance and literature recommendation.

The students worked on proofs of performance in teams of two or three. The proofs were related to the two original modules that were merged in the workshop series. For "Social Nets", the students wrote a paper concerning a small students' research project on topics such as the smart city or digital dexterity. The proof of performance for "Information Technology and Its Social Context" was the creation of a portfolio. It had to contain several reflections on topics such as ethics and a description of the tasks on which the students worked during the workshops. The students presented their progress in each workshop and got feedback from their peers and from me, the teacher. The milestones for the proofs of performance are: building a small team, finding and describing a topic, literature, development, final questions (for the peers and the teacher), delivery and review. Appendix D offers some details on the scope and procedure.

The students and the teacher worked together using the agile learning and teaching approach (see Appendix A.3 for more details).

\subsection{Case 1: Summer term 2017}

The workshop series started on 30 and 31 March 2017 and concluded with the eighth workshop on 22 and 23 June 2017.

\subsubsection{Students}

Five students enrolled, four men and one woman. Four of them were in their early twenties, one man about ten years older. All of them were born in Germany, two had an international background, their families coming from South-east Europe and the Middle East. Four of them had a job to make a living, at least partly. Other financial resources were provided by parents. During the first workshop they described their motivation to enrol in the social informatics study path for instance as "less technical stuff than in the other study path" and their interest in the social aspects of computer technology, information systems and digitization.

\subsubsection{Commitment}

All five students took regular and active part in the workshops. They communicated to their peers and to me (the teacher) the reasons if they could not show up. The reasons were job obligations, illness or family matters. The students worked actively and reliably together on their proofs of performance. One student engaged himself thoroughly to manage the participation in the workshop series. Due to relays in former terms he had a big workload of more classes than usual. At first it seemed that he would not be able to take part, but as he told us during the third workshop: "I really want to take part, because this workshop series is special and I do not want to postpone this for another term." Later we learned that, if this student had left, we would have had to cancel the whole workshop series, as the university requested at least five participants. All of us, his peers and the teacher, were grateful that he sorted out his schedule to take part.

\subsubsection{Success}

The students worked on proofs of performance in teams of two and three students respectively. The students' research topics were "How can we convert Furtwangen to a smart city?" and "How can 
marketing for a print medium take place in the digital era?" All five students succeeded and got good grades in both the students' research projects (one A, one B) and the portfolios (three A's, one B, one C).

\subsubsection{Satisfaction}

The students' answers during the check-in on the first day of the fifth workshop induced a dialogue on the unfamiliar learning and teaching approach.

Workshop 5:

Now at half-time of the workshop series - five out of eight are done - we draw up an interim balance. The learning setting is new in that CM-PBL requires and fosters cooperation in between the face-to-face learning days. One principle is: "Do not muse on a problem for more than two hours (for instance in Software Development). Then you ask in the forum or your buddy or an expert in our team or outside who can help you."

We use the buddy system in the portfolio and in the students' research projects. Still it is unfamiliar for the students, not just to do their task for the next face-to-face learning, but to confer with their buddies, for instance on reflections in their portfolios, to ask for and to give feedback and to discuss questions.

$[\ldots]$

The students are pleased with our learning approach with dialogues, group exercises, visualizations and the analysis of movies with reference to IT Product Management and social informatics. Unaccustomed and thus - still - requiring some effort is the project setting. This requires that the students do not perform a final sprint during the second half or later up to the end of their term, but to work from the beginning on continuously - on their proofs of performance, the portfolio and the students' research project.

(translated form the blog of 8 May 2017 - https://www.christa-wessel.de/2017/05/08/ich-lebe$\underline{\text { auch/) }}$

In summary, the students offered feedback on their experience with the workshops, new insights and degree of satisfaction in their portfolios.

Bachelor student of IT Product Management, early twenties:

Now we look at the closing words of the portfolio. They show my personal conclusion, describing my reflection on the semester overall, during which I attended the workshops in the modules "Social Nets" and "Informatics and Society". I liked the workshops overall although I'm not a person who likes to interact and to occupy centre stage. Unfortunately, I could not avoid this as our group consisted of just five students and the teacher. On the whole, this turned out to be positive, because the workshops were anything but boring lessons and indeed I had fun. The continued repetition of the subject matter lingered in the memory. Beside this I reflected intensely on my studies in IT Product Management and its parts. The flexible working style, for instance the organization of breaks and lessons, was relaxing and precious. My own learning targets were indifferent and not well defined in the beginning. I was able to shape and reach them during the semester. Besides, the inclusion of and work on topics apart from social informatics stemming from other modules were excellent. For instance we looked at quality management, feedback and presentations techniques. To sum up, I can say with good conscience that I have performed the modules "Social Nets" and "Informatics and Society" successfully.

(author's translation of the student's portfolio written in German)

During the final workshop we, the students and the teacher, performed a summative qualitative evaluation. We used questions otherwise in use for the evaluation of a consulting project with two perspectives (Weßel, 2017, pp. 247-248): (a) the client and customer, in our case the students; and (b) the service provider, that is the consultant or IT product manager, in our case the teacher, for instance: 
- Objective achieved; assessment based upon in advance defined criteria.

- Balanced budget (here: time, effort).

- Learned something new.

- Satisfaction, assessment based on predefined criteria.

- What was good? And why?

- What was not good? And why? And how to improve?

- Client: can we proceed alone? Without the service provider?

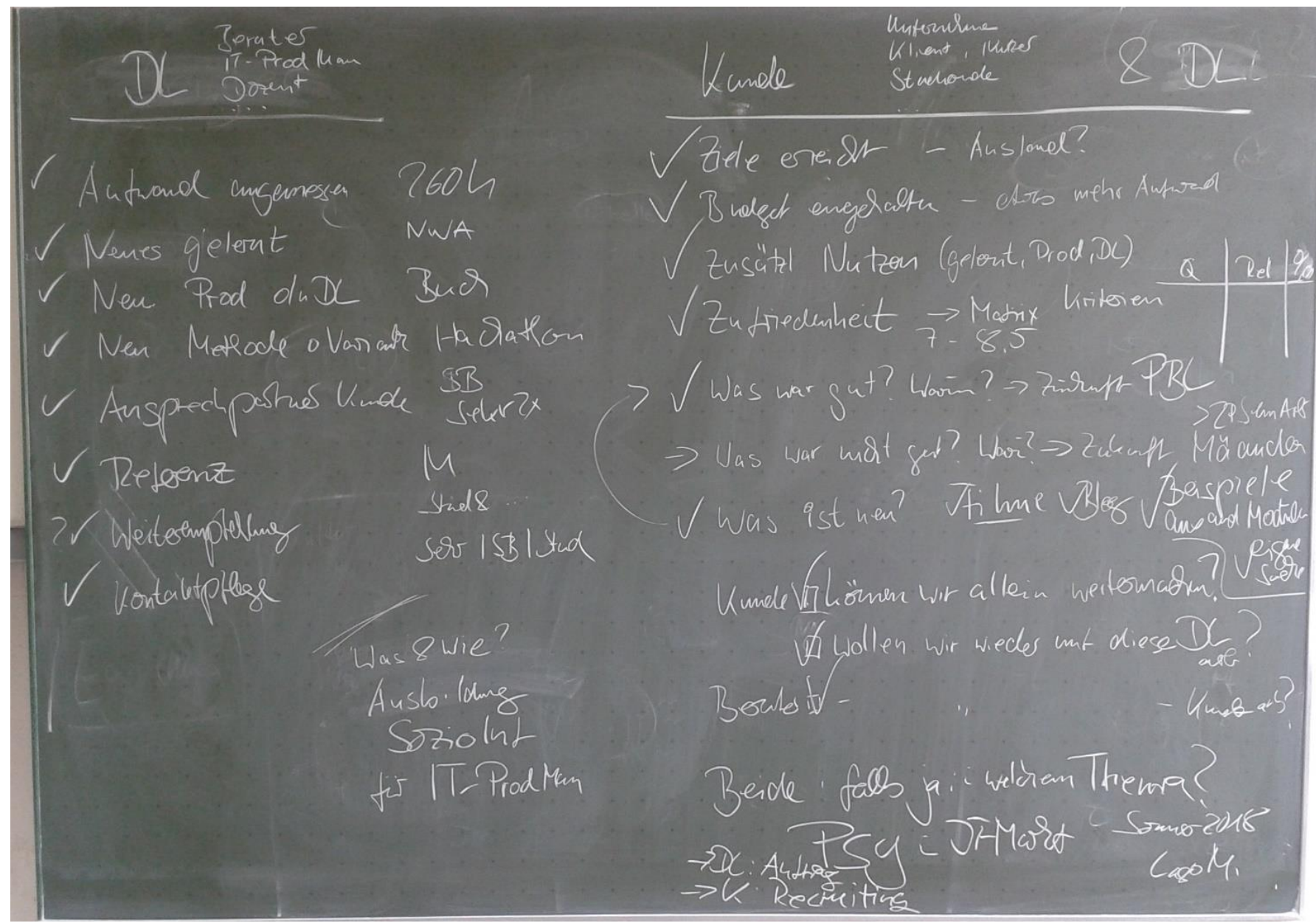

Figure 1. Summative, qualitative evaluation, Workshop 8, 23 Jun 2017.

We saw the goals of the workshop series met and were satisfied. We rated the quality of our work together in the small teams and in the large group of students and teacher between 7 and 8.5 on a scale from 1 to 10.

\subsection{Case 2: Winter term 2017/2018}

The workshop series started on 2 and 3 November 2017, and concluded with the eighth workshop on 18 and 19 January 2018.

\subsubsection{Students}

Eleven students enrolled, all male, aged between early twenties and early thirties. The cultural background was mixed. Some were born in Germany with their families coming from Germany (about half of the participants), some were born abroad and they and their families had migrated to Germany and some were born in Germany and their parents or grandparents had come to Germany. The countries were located in South-east Europe and the Middle East. Several students had a job to make a living, at least partly. Other financial resources were provided by parents. Similar to the students in case 1, the 
students described during the first workshop their motivation to enrol in the social informatics study path, for instance as "less technical stuff than in the other study path" and their interest in the social aspects of computer technology, information systems and digitization.

\subsubsection{Commitment}

The attendance rate was as follows. Ten students missed three to six of the sixteen workshop days. They communicated to their peers and to me (the teacher) the reasons if they could not show up on a day or during a whole workshop. The reasons were job obligations, illness or family matters. One student missed seven of the sixteen workshop days. In the beginning he offered no reasons to his peers or to me. I intervened in a one-to-one conversation during the third workshop and reminded the student that his participation in the workshops was crucial not only for him, but also for his peers to succeed at the proofs of performance. The other ten students worked actively and reliably during the workshops and at their proofs of performance.

\subsubsection{Success}

In the students' research project three of the four teams succeeded with a B. One group failed and got an F. The students' research topics were "Digital dexterity"; "Marketing for a musician and his media in the digital era"; "Social nets as marketing media for the selling of mobile phones" and "Gaming". One student failed with an F in his portfolio. The others succeeded: three A's, six B's and one D. The student, who failed in both the portfolio and the students' research project, was the student who had missed seven days of the workshops. This student's peers in the students' research project could not compensate for his low commitment. On the final day of the last workshop, they expressed their understanding of my obligation to assess the group's work. In advance, before I graded this students' research project with an F, I consulted with the head of teaching at the Department of Computer Science. He confirmed that I had to take this route.

\subsubsection{Satisfaction}

After the eight workshops, the eleven students filled in an evaluation questionnaire provided by the university. In both the descriptive statistical part and in the qualitative part, the students described their satisfaction with the quality of the teaching and their own contributions as high and their workload as appropriate. Furthermore, the students described their experience in the portfolios.

Bachelor student of IT Product Management, early twenties:

What was extraordinary during these workshops, we were asked during our tasks to think for ourselves and not always to use the internet. Thus one should be able to gain independence of digitization, otherwise one would go daft.

(author's translation of the student's portfolio written in German)

Bachelor student of IT Product Management, early twenties:

The overall reflection becomes my final words in this portfolio, to be read as conclusion. Here I go into the workshops and not into the contents of the portfolio so far. Through these workshops I became acquainted with a new way of learning. The workshops so far are very well structured and have brought more fun than any dry lecture or seminar. Thus, time passed remarkably faster, because we moved a lot and one had always something to do. Beside this, I like a lot that movies can bring us important insights, because this brought modern methods to the fore. I see the peer reflection $\left[{ }^{*}\right]$ during the first part of a particular workshop on the topics of the previous workshop as a useful method, because more than expected is kept in memory.

In addition I gave thoughts to my study programme "IT Product Management" and I faced intensely up to its components. Furthermore, I appreciated the conjunction of social informatics with problems, questions 
or tasks from other modules of this term, for instance certain components like leadership and team building $[\ldots]$.

In conclusion, I can say I have gained a new repertoire of knowledge and I discern in my case a constant learning process.

(author's translation of the student's portfolio written in German)

[*] Peer reflection: Two students discuss with the others the topics of the previous workshop, using anything but a presentation. Often they developed and used special quizzes and other games. This takes about twenty to thirty minutes and follows the learning by teaching approach.

\subsection{Cases 1 and 2: Workload}

The Bologna Process expects 25 to 30 hours per credit (European Commission/EACEA/Eurydice, 2020, p. 10). 60 credits correspond to a full-time equivalent academic year, 1500-1800 hours. The workshop series covered two modules with 90 hours of face-to-face learning (contact hours) and expected 270 hours of self-study, resulting in 12 credits. This corresponds to 30 hours per credit.

The students in case 1 and case 2 described their overall workload including the proofs of performance as slightly higher than in other seminar settings, but adequate. In contrast to traditional approaches, the students reported a different distribution of their workload during the term (see paragraph 4.5.4 "Satisfaction").

The teacher's workload as a visiting lecturer comprised preparation, execution and post-processing of the teaching and also reviews of the proofs of performance and communication with the university administration. During my projects, I keep a logbook with the dates, events, work done and the hours spent. There were 120 teaching units in each term, 45 minutes each. This sums up to 90 hours. In case 1 , my workload was 238 hours; this corresponds to 2 hours per teaching unit. In case 2, it was 129 hours, which means 1.1 hour per unit. The larger amount of workload during case 1 is related to the design of the seminar with its workshops and to the detailed documentation of the workshops in the blog, publicly accessible for the students and other interested people. During case 2, I did without a detailed documentation in the blog and referred the students to the blog entries of the previous term, as the content of the workshops were similar. The overall workload was 367 hours for 240 teaching units. The rate of 1.5 hours working load per teaching unit corresponds to former experience in the first and second runs of a seminar. Other freelance lecturers (visiting lecturers) told me that their workload was similar, sometimes higher for the first and second runs of a seminar.

What is not included, but of course done and thus needs to be added, is the time to keep up with the social informatics discipline. I tried in vain to find recent surveys and studies on teachers' workload and faculty's workload. Perhaps I failed in my research or the topic is not of peculiar interest. Nevertheless, I would like to recommend the University of Dayton's "University Faculty Workload Guidelines" (2011). It is a holistic overview and also puts an emphasis on the need for teachers' continuous learning: "A faculty member who is teaching twelve semester hours per semester can be expected to spend at least an additional twentyfour clock hours in teaching-related activities, including keeping up with her/his discipline." (University of Dayton, 2011, p. 6; p. 2 in the PDF).

\subsection{Study programme for social informatics: students' design}

On 23 June 2017, during the final workshop of case 1, the students developed a study programme for social informatics. The leading question was: "What should students learn and how would you implement it?" The students used the $8+1 \mathrm{~W}$ questions and sketched a mind map. The $8+1 \mathrm{~W}$ questions comprise (Weßel, 2017, pp. 33-40): What for? objective; Why? motivation and cause; What? contents and tasks; Who? roles and functions; Whom for? target group, client, customer; hoW? methods; When? timescale and 
appointments; Where? places; and Where from? data, information, theories, models, concepts, publications, reports, documentations, contact persons.

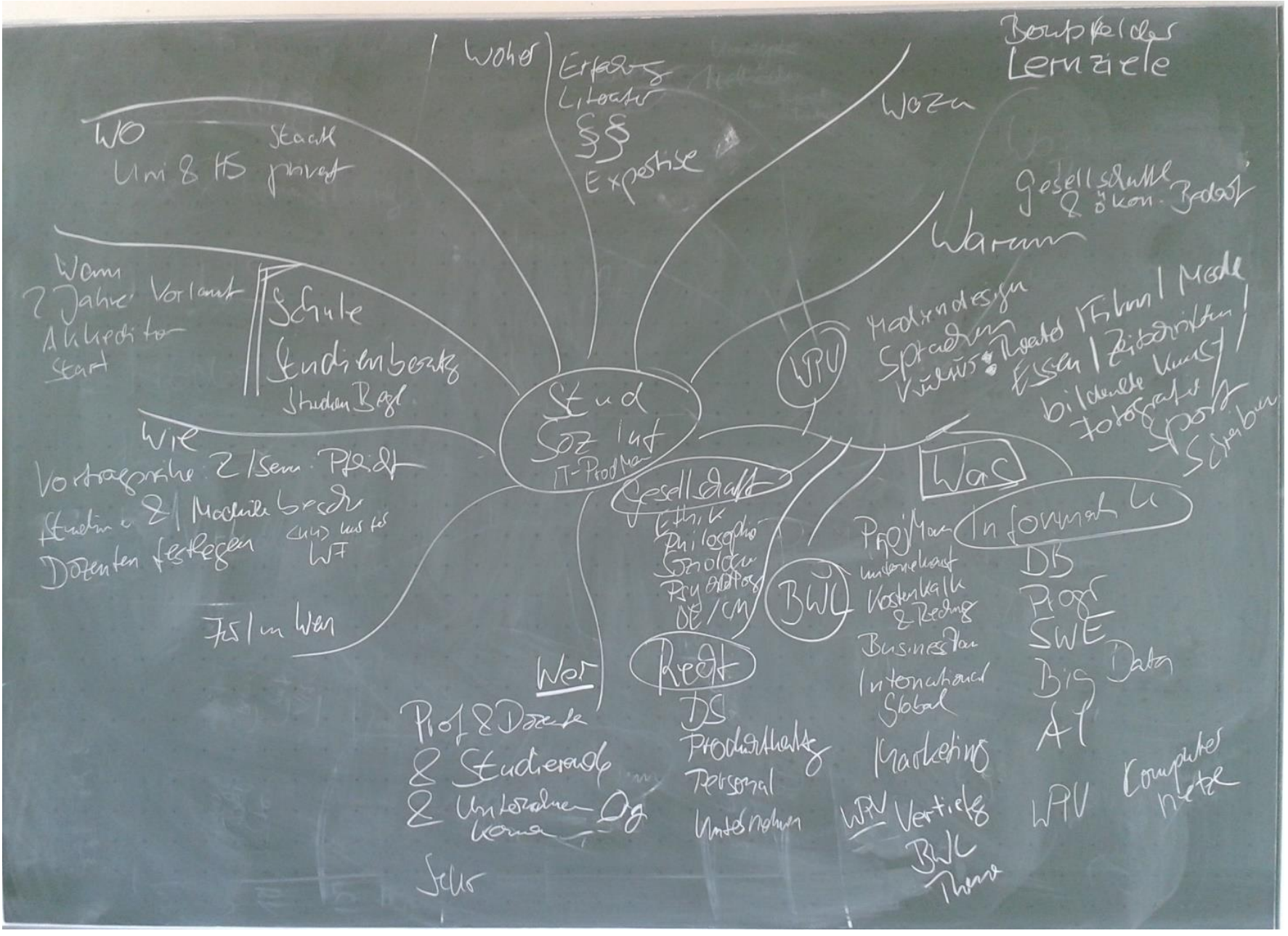

Figure 2. Design of a study program social informatics.

Students, future students and other stakeholders, such as university administration staff, teachers, education authorities and companies build the target audience. The students put an emphasis on topics and classes for the fields of informatics, economics, sociology and elective subjects. Especially elective subjects offer the opportunity to think outside the box and to learn together with students and teachers of other study programmes and departments and with experts and organizations beyond the bounds of the university, for instance with an artist, a restaurant or a magazine publishing house. In the sense of useroriented software development, the students voted for the inclusion and cooperation of all stakeholders from the very beginning of study programme design and implementation: students, teachers and university administration.

\section{Discussion}

Social informatics is an emerging and important field in the digital era (Smutny, 2016; Smutny and Vehovar, 2020). Thus, students need training in the topics, in scientific and other professional methods and the opportunity to consolidate and expand their social skills (Smutny, 2016; Weßel and Spreckelsen, 2009).

The topics of SI can be differentiated into technical and sociological parts (Smutny, 2016; Smutny and Vehovar, 2020). The workshop series presented in this paper covers two modules for students in the bachelor programme "IT Product Management" at the HFU. It focuses on the sociological aspects of social 
informatics. The learning and teaching approach is based upon the theories and concepts of competencybased learning (CBL) and uses concepts, methods and tools of continued multidisciplinary project-based learning (CM-PBL), agile learning and teaching (ALT) and blended learning (BL). Agile working methods such as Scrum were adapted to the needs of students and the teacher during a workshop series with two proofs of performance. (For references on CBL, CM-PBL, ALT and BL see "Learning and Teaching" above, and Appendix A "Learning concepts".)

The questions that occurred were "How can the concepts of CM-PBL and agile learning and teaching be transferred to a one-term seminar setting in social informatics?", "Does it work?", "Why does it work?", "What is necessary to make it happen?" Case studies can answer questions how and why, striving for a deep understanding, using qualitative and quantitative methods and considering the four principles of triangulation in methods, data sources, a researcher and also theories and suppositions (Ammenwerth et al., 2003; Stake, 1995, pp. 107-120; Yin, 2018, pp. 127-129). The study "Social Informatics Experience", performed by one researcher, triangulates in methods, data sources, theories and suppositions.

The study showed a high student commitment, success and satisfaction and an appropriate workload for both students and the teacher. Three conditions built the basis for the success, each one mandatory: the context at the university, the participating students and the teacher's background.

The university staff was open-minded towards the introduction of a new learning and teaching approach. The head of the Department of Computer Science, the head of teaching, other professors and the office assistants at the Department of Computer Science aided the teacher, herself a visiting lecturer. The fact that the modules "Information Technology and Its Social Context" and "Social Nets" had their first run in the new study programme "IT Product Management" may have fostered this.

A further component of the context is the learning environment. The layout of rooms and buildings is very important for human well-being and thus their work (Hall and Hall, 1975; Hundertwasser, 1985/1991). The university provided for the workshop series a large and well-lit room with windows on both sides, which could be opened and allowed thorough airing. The large room of about 180 square meters afforded us to work not in the conventional desk row using the chalk and talk technique but to adapt the positioning to a large refectory-style table where all could be seated plus further tables for group work and to gain space for work in the room, for instance standing in a circle during the check-in and check-out. Furthermore, large blackboards for the visualisations also helped avoid paper and pencil waste. As virus concentration, and thus risk of infection, is higher indoors (Buonanno et al., 2020), one of the preventive measures during the COVID-19 pandemic is airing the rooms. The WHO offers a roadmap with an extended glossary and scientific references on what can be done and how (WHO, 2021a). The large room, the small number of students and observing the preventive measures on hygiene, distance and wearing of face masks would have allowed to perform face-to-face learning and teaching even during many weeks of the COVID-19 pandemic in 2020/2021. Perhaps this encourages architects, administrations, teachers and students to vote for such places and to use them also during a pandemic that requires keeping distance. The "e"-part of blended learning, e-learning, is a wonderful tool, but it cannot replace the experience and benefits of face-to-face learning and teaching. Together, in blended learning, they are strong (Bleimann, 2004; Paul and Jefferson, 2019; Todd et al., 2017).

The students - five in case 1 and eleven in case 2 - showed high commitment, except one. The other fifteen were open for new learning approaches and showed willingness to participate and contribute. They were reliable, full of ideas and suggestions and showed a delightful sense of humour. The formative and summative evaluation showed that the small number of students, the learning and teaching approach and the teacher's experience in the fields of social informatics and organization development, plus the students' willingness, were crucial for the students' satisfaction. In their portfolios students described their satisfaction and learning success as higher than in conventional settings. An example of a conventional setting is a seminar of two units per week combined with a weekly lecture series and a proof of 
performance at the end of a term (seminar paper, written or oral exam). One of the characteristics of the "Social Informatics" workshop series is the use of realistic scenarios. Learning in realistic scenarios is based on the theory of cognitive learning: learning by insights and on a model empowers the learner to explore a topic autonomously, to use scientific methods and to develop solutions. This enhances the learner's motivation and improves the learning outcome in the short, medium and long term (Felder et al., 2000; Slavin, 1996).

The teacher, that is me, is a physician with a master degree in public health. I work as an organization developer with companies and single clients. This facilitated use of theories, concepts and methods of organization development (OD) for the design, implementation and evaluation of the workshop series. $\mathrm{OD}$ is based on humanistic values, such as the well-being of the individual, education and social responsibility (Argyris and Schön, 1978; Cooperrider et al., 2008; Cummings, 2008; DeMarco and Lister, 1999; Laloux, 2014; Senge, 2006; Sennett, 2012; Wiegers, 1996). This opens a door for respectful and, due to the use of OD methods, effective and efficient teacher-student cooperation at eye level. The workload of 1.5 hours per unit, including the face-to-face time, may seem low. This was possible because of my experience (more than fifteen years as a teacher, researcher, OD consultant and business coach) and a structured and well-defined process plus - and especially important - the students' commitment and cooperation. In my early teaching years the workload was higher. I am also a scientist. My research and development topics include web-based systems in health care, sociology and informatics, quality management in health care and also didactic and higher education. Thus, I could perform a case study as a participating observer on the implementation of social informatics teaching. Other teachers surely will have different backgrounds. Subject-specific, methodological and social skills are mandatory. The willingness to see oneself as a facilitator, mentor, guide and to appreciate the students is useful (Cooperrider et al., 2008; Laloux, 2014; Senge, 2006; Sennett, 2012; Weßel and Spreckelsen, 2009; Wiegers, 1996).

Both the students and the teacher can be seen as "mirrors" of social informatics and its diversity. The reflections include different countries, educations, professions (including the students), age, gender, cultures, interests, characters and attitudes to life in general, work and learning. The setting as a series of eight two-day workshops with breaks of several weeks in between in a comfortable seminar room offered time and space to develop and appreciate a productive learning and teaching experience.

These, then, are some answers to the questions "How can the concepts of CM-PBL and agile learning and teaching be transferred to a one-term seminar setting in social informatics?", "Does it work?", "How does it work?" and "Why does it work?" The conditions and context at the HFU in 2017 and early 2018 were well suited for the implementation of such a workshop series. Open-minded professors and members of the university administration supported the work of the visiting lecturer. Students are interested in such settings in any case (Donnelly and Fitzmaurice, 2005; Felder et al., 2000; Merseth, 1991; Pape et al., 2002; Slavin, 1996; Weßel and Spreckelsen, 2009). This leads to the research question "What is necessary to make it happen?" What can teachers and other stakeholders in learning and teaching at universities do to make such settings happen beyond conventional weekly flows? My answer as an organization developer is not strictly in scientific language: find stakeholders who will support you, win students as allies and just go for it.

As I mentioned earlier: The purpose of the study "Social Informatics Experience" is to offer the reader an example and thus inspiration for how students can learn social informatics holistically. The learning and teaching approach is not restricted to SI. It can be used for other topics and fields. The design of the seminar as a workshop series, the data and the conclusion are intended to be used and perhaps useful in further research, decision making and application especially in the multi- and trans-disciplinary field of social informatics. 


\section{Conclusion and Outlook}

The students' design of a study programme in social informatics in case 1 (section 4.8) shows that these and I suppose, other - students are aware of the multi-disciplinarity of social informatics and the needs to train in fields such as informatics, economics, sociology and elective subjects.

Nowadays the term social informatics is not widely known and sometimes misunderstood in science, in education and in society (Smutny 2016; Smutny and Vehovar, 2020). The misunderstanding refers to the field of the development of information technology in the area of welfare and social service work, similar to health informatics and its applications. The low degree of familiarity may be caused by the fact that many scientists, practitioners and teachers work in one of the many fields of social informatics and name just their particular field such as knowledge management, social media and World Wide Web or digitization and other perspectives such as ethics, law, economics and e-government. Smutny and Vehovar (2020, p. 529) describe the situation as follows:

The problems with a common SI research denominator are all the more troublesome because SI addresses a broad area related to the interaction between society and information and communication technology (ICT), where many established disciplines already exist. On the other hand, there also appears to be a certain lack of conceptual grounding in some SI research, meaning it does not belong to any school of SI.

Furthermore, SI is communicated nowadays using several terms, such as "social informatics", "socioinformatics" (Stellenbosch University, 2021a and b) and "socioinformatics" (TU Kaiserslautern, 2021). There is a need to communicate social informatics and the variations of the term in science, in education, in the workplace and wherever it seems appropriate. Scientists, teachers and practitioners can draw the attention of stakeholders in social informatics - university administrations, policymakers in government, economics and elsewhere plus the public, represented for instance by journalists and media - to both the benefits of information technology and the hazards, for instance the misuse of social media (Darius and Stephany, 2020). The experience with the COVID-19 pandemic shows how information technology, sociology, psychology, philosophy (ethics) and social informatics can contribute to the mastering of a pandemic and other challenges.

\section{Additional Information and Declarations}

Acknowledgements: Colleagues and students for their support and encouragement, especially Nastassia Lunitz for comments on the early drafts of this paper.

Conflict of Interests: The author declares no conflict of interest.

Author Contributions: The author confirms being the sole contributor of this work.

Data Availability: The data that support the findings of this study are available from the corresponding author. 


\section{Appendix A: Learning Concepts}

\section{A.1 Competency-based learning (CBL)}

Learning with hand, heart and mind - stimuli and use of the haptic sense - is a well-tried and sciencebased approach. More than two hundred years ago, the pedagogue and educational reformer Heinrich Pestalozzi (1746-1827) developed substantial fundamentals in learning and education. The association "Pestalozzi im Internet" (2021) offers a comprehensive documentation and introduction to his work and life. Methods used in competency-based learning (CBL) build upon this approach.

Students need a comprehensive education in subject-specific, methodological and social competencies and skills. The purpose of CBL is to empower students to develop these skills (Jones et al., 2002). Dewey (1997 and 2008), Schön (1983), Argyris and Schön (1978 and 1995) and Biggs (2011) provided the basis for CBL: Dewey with experiential learning, Schön with the reflective practitioner, Argyris and Schön with theory in use and theory of action plus double-loop learning, and Biggs with constructive alignment. Casebased and project-based learning (PBL) use the theories and concepts of CBL (Donnelly and Fitzmaurice, 2005; Felder et al., 2000; Merseth, 1991; Pape et al., 2002). The approach is to learn in realistic scenarios.

Learning in realistic scenarios is based on the theory of cognitive learning: learning by insights and on a model empowers the learner to explore a topic autonomously, to use scientific methods and to develop solutions. This enhances the learner's motivation and improves the learning outcome in the short, medium and long term (Felder et al., 2000; Slavin, 1996). Teachers envision themselves as facilitators, mentors and guides (Weßel and Spreckelsen, 2009). Braband and Andersen expressed this in their film "Teaching Teaching \& Understanding Understanding" (2006).

\section{A.2 Continued multidisciplinary project-based learning (CM-PBL)}

Problem-based learning was developed for law classes at the Harvard University in the nineteenth century (Merseth, 1991). Realistic cases introduced the students to the topic and trained them in juristic thinking and decision making. Medical schools adapted this approach as problem-based learning, which was widely used from the 1970s on (Neufeld and Barrows, 1974; Van der Vleuten et al., 2004). Other fields, such as computer science and economics, broadened the perspective and introduced project-based learning (Bleimann, 2004; Felder et al., 2000; Haux et al., 2004; Pape et al., 2002).

During a research and development project that lasted from 2002 to 2007, focused on web-based information and mobile systems in health care, Weßel and Spreckelsen (2009) introduced continued multidisciplinary project-based learning (CM-PBL). Students entered the research group to work on their thesis: student's research projects (similar to a bachelor thesis), diploma (similar to a master degree) and doctoral theses. Two scientists were co-teachers and supervisors. One of them performed the project management. The students developed in their theses parts of a web-based and several mobile systems or performed evaluations. The teachers did research and development too, and thus, both teachers and students proceeded with their scientific work. The project environment strengthened team identity and team work and improved students' performance and research results. Furthermore, the teachers' benefit was to train alternative teaching. The attitude of being a facilitator, mentor and guide for the students was fostered by the project setting and the structured cooperation of the two teachers in the formative assessment and support of the students. Based on this experience, I have used the CM-PBL approach in several one-term and two-term seminars since 2009. The necessary adaptation is facilitated by the use of agile learning and teaching methods.

\section{A.3 Agile learning and teaching (ALT)}

Focus on the customer and the development of a working product, appreciate staff and colleagues, work cooperatively, flexibly and swiftly. The Agile Software Development concept offers values and principles 
to work in this way (Beck et al., 2001). Several agile methods have been developed (Cohen et al., 2005). They could build upon previous developments (Larman and Basili, 2003). One of these is the holistic approach, which emerged in product development during the 1980s, for which Takeuchi and Nonaka (1986) used the rugby metaphor and introduced Scrum with it: the teams work as a whole to get the ball up the field or to develop a product (scrum is a move in rugby to restart the game).

Meanwhile, agile approaches are also used as managerial tools (Denning, 2018) and in education (Babb and Norbjerg, 2010; Layman et al., 2006). An "agile" seminar based on the Scrum framework offers the students the opportunity to use the agile approach and to learn how to use it in their professional life. Weßel (2019, pp. 141-146) describes the application.

Adapting Scrum has to consider five aspects:

- Teamwork: the teacher as a team developer and formative evaluation;

- Setting: workshops instead of 90-minute events;

- Scrum translated: products, roles, artefacts and meetings;

- Working products from the beginning on: proofs of performance;

- Final evaluation and acceptance.

The students and the teacher build a group. Group dynamics (Tuckmann, 1965; Tuckman and Jenssen, 1977) shows that considering the steps of forming, storming, norming, performing and adjourning helps build a group and a team and work efficiently, effectively and satisfyingly together. For the distinction between a group and a team, see Levi (2007, pp. 4-6).

Such an approach is time-consuming. Workshops that last for an afternoon, a day or two days and intervals of one, two or three weeks afford to perform the five steps of group dynamics during each workshop and the whole term. During the workshops, students can work on tasks in small groups and present and discuss the results with their peers. During the intervals, students can work on their proofs of performance and other tasks.

The formative evaluation can take place as warming-up at the beginning and wrap-up at the end of each day as check-in/check-out (Weßel, 2019, p. 226). Questions in Scrum are for instance: "What have I done since yesterday?", "What will I do today?", "What inhibits me?" Check-in/check-out serve to evaluate formatively the quality of the teacher's and students' work. This enables them to improve their work. Furthermore, check-in/check-out can demonstrate the students' and teacher's shape (fitness, workload beside this seminar, etc.). For instance, the teacher can ask "How did the last week go?" on the first day of a workshop in the morning. In the evening, she can start the sentence: "Come to think of it..." The students and the teacher stand in a circle (work in the room) and each student and then the teacher answer the question. This takes about five minutes with five to fifteen students and one teacher. The findings of the check-in/check-out enable both teacher and students to adapt their work accordingly.

The first sentence of this section can be adapted to agile learning: as the teacher focus on the students, as a student focus on learning; as the teacher produce high-end teaching, as a student produce high-end proofs of performance; all: appreciate each other, work cooperatively, flexibly and swiftly.

The students work on proofs of performance in teams of two or three. They write a paper concerning a small student research project (in SI on topics such as smart city or digital dexterity). Another proof of performance is the creation of a portfolio that contains several reflections on topics such as ethics and a description of the tasks the students work on during the workshops. The students present their progress in each workshop and get feedback from their peers and from the teacher. The milestones of the proofs of performance are: building a small team, finding and describing a topic, literature, development, final questions (for the peers and the teacher), delivery, review. Products, roles, artefacts and meetings in Scrum can be translated to agile learning. 
- Products: proofs of performance and exercises during and between the workshops.

- Roles: teacher: scrum master (team developer) and product owner (reader of proofs of performance); students: developers (writing proofs of performance) and product owners (reading others' proofs of performance).

- Artefacts

○ Vision: description of the proofs of performance

- Product backlog (requirements): learning objectives

- Sprint backlog (tasks): milestones; students' oral reports on their progresses

- Burndown chart (done): documentation

○ Impediment backlog (impediments): students' oral reports on questions and impediments

- Product increment (software): proceeding proofs of performance

Scrum-inspired meetings during the term are

- Day 1: release planning: working approach, proofs of performance: groups and topics.

- Each following workshop: sprint (iteration) planning and sprint review: see above, the milestones.

- Daily stand-up meeting: check-in/check-out on each workshop day.

- Last day: sprint retrospective: final reflection and evaluation.

The students deliver their proofs of performance two weeks ahead of the last workshop via the e-learning platform. The teacher annotates the students' files and delivers a review for each a few days ahead of the final workshop. Thus, the group can perform a summary reflection and evaluation on the last day of the seminar. Three questions build the basis:

- What is your proof of performance about?

- What were your experiences during your work on it, as a group and personally?

- The teacher's reviews: Where do you agree and where not? Why? Do you have further questions?

Finally the teacher sums up the learning and teaching and the work together and gives an outlook on future seminars. Then it is time for the social part of the adjourning period in the process of group dynamics: coffee and cake. The students' joint work on research projects and other tasks fosters the learning effects. The tools of blended learning support the work between the face-to-face units.

\section{A.4 Blended learning (BL)}

Blended learning consists of three parts, each of it with its significant meaning (Kerres, 2003; Weßel, 2019). Classroom learning (face-to-face learning) means that students and the teacher work together in one room. Methods include dialogue, group exercises and presentations, learning by teaching (a student becomes a teacher for a certain topic) and scenario developments (students develop stories, games and movies). During self-study students explore a topic and engage themselves with it, alone and with peers. E-learning allows students' and teachers' use of platforms, clouds and communication tools for cooperation: communication, data and file storage, use of libraries, for instance books, papers, films, etc.. The COVID19 pandemic, which started in January 2020, required restriction of classroom learning as one means of the preventive measure "keeping physical distance" (WHO, 2021b). Nevertheless, nothing can replace personal contact in learning, working and other social encounters (Bleimann, 2004; Paul and Jefferson, 2019; Todd et al., 2017). 


\section{Appendix B: Organization Development in Learning and Teaching}

Organization development (OD) deals with the cooperation of people in companies, administrations, universities, schools, hospitals, associations, unions, political and other organizations. OD is based on theories, insights and methods from sociology, psychology, economics and didactics. The goal and purpose of OD is to pilot change for the well-being of both the organization and the people inside and beyond it (Argyris and Schön, 1978; Cooperrider et al., 2008; Cummings, 2008; DeMarco and Lister, 1999; Laloux, 2014; Senge, 2006; Sennett, 2012; Wiegers, 1996).

OD can be applied transorganizationally, organizationally, in a department, in projects and other settings, wherever people interact. OD came into being during the 1940s and 1950s. It is based on humanistic values, such as the well-being of the individual, education and social responsibility. The approach is systemic. This means to see the environment and parts of it as complex constructs, which are in turn parts of other complex constructs. Broadly speaking, OD assumes that an organization prospers if the people in it prosper. The top management and consecutively the management and the staff are in charge together to make it happen. This is a perpetual endeavour. For the organization, "prosperity" includes economic, social and ecological success, regardless whether it is a production or service company, a profit-oriented company or a non-profit institution, an administration body or anything else. For people, "prosperity" means health, appreciation, comfort, satisfying and demanding but not overwhelming work, the opportunity to develop personally and one's career plus a proper salary. Transferred to the implementation of a seminar, this means that a teacher as the OD manager in charge adopts this attitude and integrates students - the OD staff - and the university administration and colleagues - OD staff and management - into the design, planning, management and implementation process of a particular seminar. The students' salary is their learning, success and certificate.

\section{Appendix C: Social Informatics Curriculum}

The curriculum for the Social Informatics workshop series has been available for students and the public in German since 2017 and also in English since December 2021 (Weßel, 2018). The following lists the pages and their URL and gives a short introduction for each.

\section{Social informatics}

\section{https://www.tosaam.de/seminar/social-informatics/}

This is an introduction to the field, the target audience and purpose of education in social informatics (SI), an overview on contents and learning objectives and a definition of SI.

\section{SI | Questions}

https://www.tosaam.de/seminar/social-informatics/si-questions/

This contains the questions that led to the identification of the workshop topics, considering and integrating the requirements and contents that the university had included in the description of the modules. The page starts with:

Questions are the strongest tools in research, development and learning. To answer the question "What is Social Informatics?" answers to further question can be helpful, to draft and perform RED and learning $\mathcal{E}$ teaching, for instance the SI workshop series, described on these pages.

The page continues with the questions, forty-one in total.

\section{SI | Workshop Series}

https://www.tosaam.de/seminar/social-informatics/si-workshopseries/ 
This describes in short the field of SI applied in the field of IT Product Management, because the workshops series was part of the study path on SI in the bachelor programme "IT Product Management" at the HFU. It continues with an introduction to the learning objective and the learning and teaching methods.

\section{SI | content and learning objectives}

\section{https://www.tosaam.de/seminar/social-informatics/si-content/}

The workshop series merge the two modules "Information Technology and Its Social Context" and "Social Nets". This page lists the contents (topics), the learning objectives and the proofs of performance.

\section{SI | sequence - summer term 2017}

https://www.tosaam.de/seminar/social-informatics/si-summer2017/

This gives an overview on the workshop series, the documentation, and how content and learning objectives are connected. The description of each of the eight workshops is followed by dates, topics, milestones of the proofs of performance and - where applicable - students' tasks for the following workshop.

The eight workshops are:

1. Getting started: Social net and electronic media.

2. Exploration and evaluation: What do the users need?

3. Internationalization and globalization: Life is a net.

4. Product management and ethics: The art of balance between the technically feasible and social consequences.

5. Life world and work world: In fact I live while I work.

6. Hackathon: Let's work ... and have fun.

7. Digital Dexterity and Internet of Things: About handling the new.

8. Synopsis: It's all about communication.

\section{SI | sequence - winter term 2017/2018}

\section{https://www.tosaam.de/seminar/social-informatics/si-winter2017/}

This is analogical to "summer term 2017".

\section{SI | proofs of performance}

https://www.tosaam.de/seminar/social-informatics/si-proofs/

For the module "Information Technology and Its Social Context", the proof of performance is a portfolio. For the module "Social Nets", it is a students' research project in small groups. This page offers links to the assessment criteria and explains the submission procedure to be followed by the students. Furthermore, it gives recommendations on how to approach the proofs of performance.

\section{SI | portfolio}

https://www.tosaam.de/seminar/social-informatics/si-portfolio/

This page describes in detail what the purpose of a portfolio is, how the students work on it, the learning objectives, the review process and the assessment criteria.

\section{SI | students' research project (SRP)}

https://www.tosaam.de/seminar/social-informatics/si-srp/ 
This is analogical to "portfolio".

\section{SI | Literature}

\section{https://www.tosaam.de/seminar/social-informatics/si-literature/}

This lists the literature recommended by the teacher.

\section{Appendix D: Proofs of Performance}

The students worked on proofs of performance in teams of two or three. The proofs are related to the two original modules that were merged in the workshop series. For "Social Nets", the students wrote a paper concerning a small students' research project on topics such as the smart city or digital dexterity. The paper comprised about ten pages per person (this is twenty to thirty pages $+/$ - ten percent) plus cover, table of contents, abbreviations, figures, references and - if the authors decide to include them - glossary or alphabetical index. One page covers about 1500 characters including blanks. The proof of performance for "Information Technology and Its Social Context" was the creation of a portfolio. It had to contain several reflections on topics such as ethics and a description of the tasks the students worked on during the workshops. The portfolio comprised at least twenty pages plus cover etc. (see above). For the students and other interested readers, I described the SRP and the portfolio in the blog entry of 24 February 2017, and in the online curriculum on sub-page "proofs" (Weßel, 2018):

Students' research project (SRP):

In information technology and other areas you develop products and services following the steps of analysis, design, implementation and evaluation. Design a draft for the development and implementation of a digital social network of a company. Or: Design a draft for the marketing of a product or a service. Use the 8+1 W. Include network analysis in the design. Use methods of qualitative field research and software engineering, including agile methods. Take into account social conditions that have an impact, for instance historical, political, cultural, economic and media-driven aspects.

Work during the term on a portfolio:

a) write a reflection on a number of topics due to targeted days,

b) assemble your work done during the workshops (visualisations and others),

c) introduce your students' research project in the module "Social Nets": (co-)authors, title and abstract,

and find a peer with whom you cooperate as a buddy team: you will present your buddy's reflections [in (a)] to the course and enter a dialogue.

The students presented their progress in each workshop and got feedback from their peers and from me, the teacher. The milestones of the proofs of performance are: building a small team, finding and describing a topic, literature, development, final questions (for the peers and the teacher), delivery and review. The students and the teacher worked together using the agile learning and teaching approach (see Appendix A.3 for more details).

\section{References}

Ammenwerth, E., Iller, C., \& Mansmann, U. (2003). Can evaluation studies benefit from triangulation? A case study. International Journal of Medical Informatics, 70(2-3), 237-248. https://doi.org/10.1016/s1386-5056(03)00059-5

Argyris, C., \& Schön, D. (1978). Organizational Learning: A theory of action perspective. Addison Wesley.

Argyris, C., \& Schön, D. (1995). Organizational Learning II: Theory, Method, and Practice. FT Press.

Babb, J., \& Norbjerg, J. (2010). A Model for Reflective Learning in Small Shop Agile Development. In J. Molka Danielsen, H. Nicolajsen, \& J. Persson (Eds). Information Systems Research Seminar in Scandinavia Nr. 1: IRIS 33. (pp. 23-38). tapir akademisk forlag. 
Beck, K., Mike Beedle, M., van Bennekum, A., Cockburn, A., Cunningham, W., Fowler, M., Grenning, J., Highsmith, J., Hunt, A., Jeffries, R., Kern, J., Marick, B., Martin, R., Mellor, S., Ken Schwaber, K., Sutherland, J., \& Thomas, D. (2001). Manifesto for Agile Software Development - The Mainfesto - Principles - History. http://agilemanifesto.org/

Biggs, J., \& Tang, C. (2011). Teaching for Quality Learning at University. 4th edition. Open University Press.

Bleimann, U. (2004). Atlantis University:a new pedagogical approach beyond e-learning. Campus-Wide Information Systems, 21(5), 191-195. https://doi.org/10.1108/10650740410567536

Brabrand, C., \& Andersen, J. (2006). "Teaching Teaching \& Understanding Understanding" 19 minute award-winning shortfilm about Constructive Alignment. University of Aarhus, Denmark. https://www.youtube.com/watch?v=iMZA80XpP6Y (1/3) \& https://www.youtube.com/watch?v=SfloUd3eO M (2/3) \& https://www.youtube.com/watch?v=w6rx-GBBwVg (3/3)

Buonanno, G., Stabile, L., \& Morawska, L. (2020). Estimation of airborne viral emission: Quanta emission rate of SARS-CoV2 for infection risk assessment. Environment International, 141, 105794. https://doi.org/10.1016/i.envint.2020.105794

Cohen, D., Lindvall, M., \& Costa, P. (2004). An Introduction to Agile Methods. Advances in Computers, 1-66. https://doi.org/10.1016/s0065-2458(03)62001-2

Cooperrider, D., Whitney, D., \& Stavros, J. (2008). Appreciative Inquiry Handbook. 2nd edition. Berrett-Koehler Publishers.

Coy, W. (2000). Informatik \& Gesellschaft. Informatische Technik und ihre rechtlichen, ökonomischen, politischen und sozialen Wechselwirkungen. Vorlesung SS 2000. Humboldt Universität Berlin. http://waste.informatik.huberlin.de/coy/lundG SS2000.htm

Cummings, T. (Ed.). (2008). Handbook of Organization Development. Sage Publications.

Darius, P., \& Stephany, F. (2020). How the Far-Right Polarises Twitter: 'Highjacking' Hashtags in Times of COVID-19. SocArXiv. https://doi.org/10.31235/osf.io/n6f3r

DeMarco, T., \& Lister T. (1999) Peopleware: Productive Projects and Teams. 2nd edition. Dorset House Publishing Company.

Denning S. (2018). The Age of Agile: How Smart Companies Are Transforming the Way Work Gets Done. AMACOM.

Dewey, J. (1997). How We Think. (republication, 1st edition 1910). Dover Publications.

Dewey, J. (2008). Democracy and Education. (republication, 1st edition 1916). Wilder Publications.

European Commission/EACEA/Eurydice. (2020). The European Higher Education Area in 2020: Bologna Process Implementation Report. Publications Office of the European Union. https://op.europa.eu/en/publication-detail//publication/c90aaf32-4fce-11eb-b59f-01aa75ed71a1/language-en/format-PDF/source-search

Felder, R., Woods, D., Stice, J., \& Rugarcia, A. (2000). The future of engineering education. II: Teaching methods that work. Chemical Engineering Education, 34(1), 26-39.

Hall, M., \& Hall, E. (1975) The Forth Dimension in Architecture. The Impact of Building on Behavior. Sunstone Press.

Haux, R., Ammenwerth, E., ter Burg, W., Pilz, J., \& Jaspers, M. (2004). An international course on strategic information management for medical informatics students: aim, content, structure, and experiences. International Journal of Medical Informatics, 73(2), 97-100. https://doi.org/10.1016/j.ijmedinf.2003.12.004

HFU - Hochschule Furtwangen University. (2021a). Hochschule Furtwangen. https://www.hs-furtwangen.de/ \& https://www.hs-furtwangen.de/en/

HFU - Hochschule Furtwangen University. (2021b). IT Product Management. https://www.hsfurtwangen.de/en/programmes/it-product-management-bachelor/

Hundertwasser, F. (1985/1991). The Third Skin in the Third District. In Kunsthaus Wien - Museum Hundertwasser. History \& Architecture. https://www.kunsthauswien.com/en/about-us/kunst-haus-wien/history-architecture/

Kerres, M., \& Witt, C. D. (2003). A Didactical Framework for the Design of Blended Learning Arrangements. Journal of Educational Media, 28(2-3), 101-113. https://doi.org/10.1080/1358165032000165653

Laloux, F. (2014). Reinventing Organizations. A Guide to Creating Organizations Inspired by the Next Stage of Human Consciousness. Nelson Parker.

Larman, C., \& Basili, V. R. (2003). Iterative and incremental developments. a brief history. Computer, 36(6), 47-56. https://doi.org/10.1109/mc.2003.1204375

Layman, L., Cornwell, T., \& Williams, L. (2006). Personality types, learning styles, and an agile approach to software engineering education. ACM SIGCSE Bulletin, 38(1), 428. https://doi.org/10.1145/1124706.1121474

Levi, D. (2007). Group Dynamics for Teams. Sage Publications.

Lewin, K. (1946). Action Research and Minority Problems. Journal of Social Issues, 2(4), 34-46. https://doi.org/10.1111/j.15404560.1946.tb02295.x

Merseth, K. K. (1991). The Early History of Case-Based Instruction: Insights for Teacher Education Today. Journal of Teacher Education, 42(4), 243-249. https://doi.org/10.1177/002248719104200402

Neufeld, V., \& Barrows, H. (1974). The 'McMaster Philosophy': An Approach to Medical Education. Journal of Medical Education, 49(11), 1040-1050.

Pape, B., Bleek, W., Jackewitz, I., \& Janneck M. (2002). Requirements for Project-Based Learning - CommSy as an Exemplary Approach. In R. Sprague (Ed.). Proceedings of the 35th Annual Hawaii International Conference on System Sciences. IEEE. https://dl.acm.org/doi/10.5555/820739.820867 
Paul, J., \& Jefferson, F. (2019). A Comparative Analysis of Student Performance in an Online vs. Face-to-Face Environmental Science Course From 2009 to 2016. Frontiers in Computer Science, 1(7). https://doi.org/10.3389/fcomp.2019.00007

Scholz, R., \& Tietje, O. (2002). Embedded case study methods: Integrating quantitative and qualitative knowledge. Sage Publications.

Schön, D. (1983). The Reflective Practitioner: How Professionals Think in Action. Basic Books.

Senge, P. (2006). The Fifth Discipline. The art and practice of the learning organization. Revised edition. Doubleday.

Sennett, R. (2012). Together. The Rituals, Pleasures and Politics of Cooperation. Yale University Press.

Slavin, R. E. (1996). Research on Cooperative Learning and Achievement: What We Know, What We Need to Know. Contemporary Educational Psychology, 21(1), 43-69. https://doi.org/10.1006/ceps.1996.0004

Smutny, Z. (2016). Social informatics as a concept: Widening the discourse. Journal of Information Science, 42(5), 681-710. https://doi.org/10.1177/0165551515608731

Smutny, Z., \& Vehovar, V. (2020). Social Informatics Research: Schools of Thought, Methodological Basis, and Thematic Conceptualization. Journal of the Association for Information Science and Technology, 71(5), 529-539. https://doi.org/10.1002/asi.24280

Stake, R. (1995). The art of case study research. Sage Publications.

Stellenbosch University. (2021a). Arts and Social Science. BA (Humanities) with Socio-Informatics. https://suinformatics.com/undergraduate-programmes/ba-humanities-with-socio-informatics-as-major/

Stellenbosch University. (2021b). Information Science. MA Socio-Informatics. https://suinformatics.com/postgraduateprogrammes/ma-socio-informatics/

Strauss, A., \& Corbin, J. (1998). Basics of Qualitative Research. Techniques and Procedures for Developing Grounded Theory. 2nd Edition. Sage Publications.

Takeuchi, H., \& Nonaka, l. (1986). The new new product development game. Harvard business review, 64(1), 137-146. https://hbr.org/1986/01/the-new-new-product-development-game

Todd, E. M., Watts, L. L., Mulhearn, T. J., Torrence, B. S., Turner, M. R., Connelly, S., \& Mumford, M. D. (2017). A Metaanalytic Comparison of Face-to-Face and Online Delivery in Ethics Instruction: The Case for a Hybrid Approach. Science and Engineering Ethics, 23(6), 1719-1754. https://doi.org/10.1007/s11948-017-9869-3

TU Kaiserslautern. (2021). Socioinformatics (B.Sc./M.Sc.). https://www.informatik.uni-kl.de/en/studium/studiengaenge/bm-si/

Tuckman, B. W. (1965). Developmental Sequence in Small Groups. Psychological Bulletin, 63(6), 384-399. https://doi.org/10.1037/h0022100

Tuckman, B. W., \& Jensen, M. A. (1977). Stages of small-group development revisited. Group \& Organization Studies, 2(4), 419-427. https://doi.org/10.1177/105960117700200404

University of Dayton. (2011). University Faculty Workload Guidelines. https://udayton.edu/provost/ resources/docs/facwrkld.pdf

University of Ljubljana. (2021). Faculty of Social Sciences. Master of Social Informatics. https://www.fdv.unili.si/en/study/study-at-the-FDV/masters-programmes/study-programmes/master-of-social-informatics-new

van der Vleuten, C. P. M., Dolmans, D. H. J. M., de Grave, W. S., van Luijk, S. J., Muijtjens, A. M. M., Scherpbier, A. J. J. A., Schuwirth, L. W. T., \& Wolfhagen, I. H. A. P. (2004). Education Research at the Faculty of Medicine, University of Maastricht: Fostering the Interrelationship between Professional and Education Practice. Academic Medicine, 79(10), 990-996. https://doi.org/10.1097/00001888-200410000-00021

Verein «Pestalozzi im Internet». (2021). Heinrich Pestalozzi. Comprehensive Documentation. https://en.heinrichpestalozzi.de/

Weßel, C. (2010). Software Engineering Culture in Aus- und Weiterbildung - Ein Projekt-basiertes Lehr- und Trainingskonzept. In O. Linssen, T. Greb, M. Kuhrmann, D. Lange, \& R. Höhn (Eds.) Integration von Vorgehensmodellen und Projektmanagement. 17. Workshop der Fachgruppe WI-VM der Gesellschaft für Informatik e.V. (pp. 174-183). Shaker.

Weßel, C. (2015). Agil lernen und lehren: All / Erfahrungsbericht und Reflexion. Poster zur Fachtagung "Selbstgesteuert, kompetenzorientiert und offen?!". https://www.disc.uni-kl.de/fachtagung2015/wpcontent/uploads/2015/03/Poster TUSKO\%C2\%B415 Wessel.pdf

Weßel, C. (2017). Beraten - Philosophien, Konzepte und das Projekt. Weidenborn Verlag.

Weßel, C. (2018). Social Informatics (translation of the German version in Dec 2021). https://www.tosaam.de/seminar/socialinformatics/

Weßel, C. (2019). Andere arbeiten lassen - Lernen und Lehren an Hochschulen mit dem A A L. Weidenborn Verlag.

Weßel, C. (2021a). Sozioinformatik - Von Menschen \& Computern ... und Bibern. Weidenborn Verlag.

Weßel, C. (2021b). Social Informatics. Blog (since 2011). https://www.christa-wessel.de/blog/social-informatics/

Weßel, C., \& Spreckelsen, C. (2009). Continued Multidisciplinary Project-based Learning - Implementation in Health Informatics. Methods of Information in Medicine, 48(6), 558-563. https://doi.org/10.3414/me0586

WHO - World Health Organization. (2021a). Roadmap to improve and ensure good indoor ventilation in COVID-19 context. 1 March 2021. https://www.who.int/publications/i/item/9789240021280

WHO - World Health Organization. (2021b). https://www.who.int/ 
Wiegers, K. (1996). Creating a Software Engineering Culture. Dorset House Publishing Company.

Yin, R. (2018). Case Study Research and Applications: Design and Methods. 6th Edition. Sage Publications.

Editorial record: The article has been peer-reviewed. First submission received on 28 July 2021. Revision received on 1 October 2021 and 15 December 2021. Accepted for publication on 20 December 2021. The editors coordinating the peer-review of this manuscript were Vasja Vehovar (D), Zdenek Smutny (D), and Alice R. Robbin (D). The editor in charge of approving this manuscript for publication was Zdenek Smutny.

Special Issue: Perspectives of Social Informatics.

Acta Informatica Pragensia is published by Prague University of Economics and Business, Czech Republic.

ISSN: $1805-4951$ 